\title{
The Silencing of Carotenoid $\beta$-Hydroxylases by RNA Interference in Different Maize Genetic Backgrounds Increases the $\beta$-Carotene Content of the Endosperm
}

\author{
Judit Berman ${ }^{1}$, Uxue Zorrilla-López ${ }^{1}$, Gerhard Sandmann ${ }^{2}$, Teresa Capell ${ }^{1}$, Paul Christou ${ }^{1,3}$ \\ and Changfu Zhu 1,4,* it \\ 1 Department of Plant Production and Forestry Science, University of Lleida-Agrotecnio Center, \\ Av. Alcalde Rovira Roure, 191, 25198 Lleida, Spain; jberman@hbj.udl.cat (J.B.); uxue87@gmail.com (U.Z.-L.); \\ teresa.capell@pvcf.udl.cat (T.C.); christou@pvcf.udl.cat (P.C.) \\ 2 Biosynthesis Group, Molecular Biosciences, Johann Wolfgang Goethe Universität, 60054 Frankfurt, Germany; \\ sandmann@bio.uni-frankfurt.de \\ 3 ICREA, Catalan Institute for Research and Advanced Studies, Passeig Lluís Companys 23, \\ 08010 Barcelona, Spain \\ 4 School of Life Sciences, Changchun Normal University, Changchun 130032, China \\ * Correspondence: zhu@pvcf.udl.cat; Tel.: +34-973-702694
}

Received: 28 October 2017; Accepted: 16 November 2017; Published: 24 November 2017

\begin{abstract}
Maize (Zea mays L.) is a staple food in many parts of Africa, but the endosperm generally contains low levels of the pro-vitamin A carotenoid $\beta$-carotene, leading to vitamin A deficiency disease in populations relying on cereal-based diets. However, maize endosperm does accumulate high levels of other carotenoids, including zeaxanthin, which is derived from $\beta$-carotene via two hydroxylation reactions. Blocking these reactions could therefore improve the endosperm $\beta$-carotene content. Accordingly, we used RNA interference (RNAi) to silence the endogenous $\mathrm{ZmBCH1}$ and $\mathrm{ZmBCH} 2$ genes, which encode two non-heme di-iron carotenoid $\beta$-hydroxylases. The genes were silenced in a range of maize genetic backgrounds by introgressing the RNAi cassette, allowing us to determine the impact of $\mathrm{ZmBCH1} / \mathrm{ZmBCH} 2$ silencing in diverse hybrids. The $\beta$-carotene content of the endosperm increased substantially in all hybrids in which $\mathrm{ZmBCH} 2$ was silenced, regardless of whether or not $\mathrm{ZmBCH1}$ was silenced simultaneously. However, the $\beta$-carotene content did not change significantly in C17 hybrids $(\mathrm{M} 7 \times \mathrm{C} 17$ and M13 $\times \mathrm{C} 17)$ compared to $\mathrm{C} 17$ alone, because $\mathrm{ZmBCH} 2$ is already expressed at negligible levels in the $\mathrm{C} 17$ parent. Our data indicate that $\mathrm{ZmBCH} 2$ is primarily responsible for the conversion of $\beta$-carotene to zeaxanthin in maize endosperm.
\end{abstract}

Keywords: maize (Zea mays L.); $\beta$-carotene; carotenoid $\beta$-hydroxylase; RNAi; hybrid

\section{Introduction}

Humans are unable to synthesize vitamin A de novo and must obtain this essential nutrient in their diet, either directly as retinol from animal sources or as pro-vitamin A (PVA) carotenoids from plants. The major PVA carotenoid is $\beta$-carotene, which can be converted into two molecules of retinol. The other PVA carotenoids are $\alpha$-carotene, $\gamma$-carotene, and $\beta$-cryptoxanthin, and these yield one molecule of retinol each [1]. Vitamin A in its reduced form (retinal) is necessary for rhodopsin biosynthesis, making this nutrient essential for normal vision, and it also helps to maintain healthy epithelial and immune system cells. The acidic form (retinoic acid) is a key developmental morphogen. Therefore, vitamin A deficiency (VAD) causes visual disorders in the form of night blindness and (in more serious cases) xerophthalmia, as well as epithelial and immune system defects that leave individuals, especially children, highly susceptible to infections [1-3]. The polished grain (endosperm) of cereal crops such as rice (Oryza sativa), maize (Zea mays), and wheat (Triticum aestivum) are staples in 
many parts of the world, but they contain very low levels of PVA carotenoids, hence populations that subsist on cereal-rich diets are prone to VAD [4,5]. Increasing the levels of PVA carotenoids in cereals is an effective way to combat this challenge $[1,2,4,6,7]$.

PVA carotenoids are synthesized via the methylerythritol 4-phosphate (MEP) pathway, which is also known as the non-mevalonic acid (MVA) pathway [6-8]. The first committed step in carotenoid biosynthesis is the condensation of two molecules of geranylgeranyl diphosphate (GGPP) by phytoene synthase (PSY) to produce phytoene, which is then converted into all-trans-lycopene via four desaturation and isomerization steps. Lycopene is the branching point of this pathway (Figure 1). In one branch, lycopene is cyclized to form the PVA carotenoids $\gamma$-carotene and $\beta$-carotene. The latter is oxidized to form another PVA carotenoid ( $\beta$-cryptoxanthin) and subsequently the non-PVA carotenoid zeaxanthin, antheraxanthin, and violaxanthin. In the other branch, lycopene is cyclized to produce the PVA carotenoid $\alpha$-carotene, which is oxidized to form the non-PVA carotenoids $\alpha$-cryptoxanthin and zeinoxanthin, and finally lutein. The oxidation reactions that deplete the pool of PVA carotenoids are catalyzed by enzymes known as carotenoid $\beta$-hydroxylases.

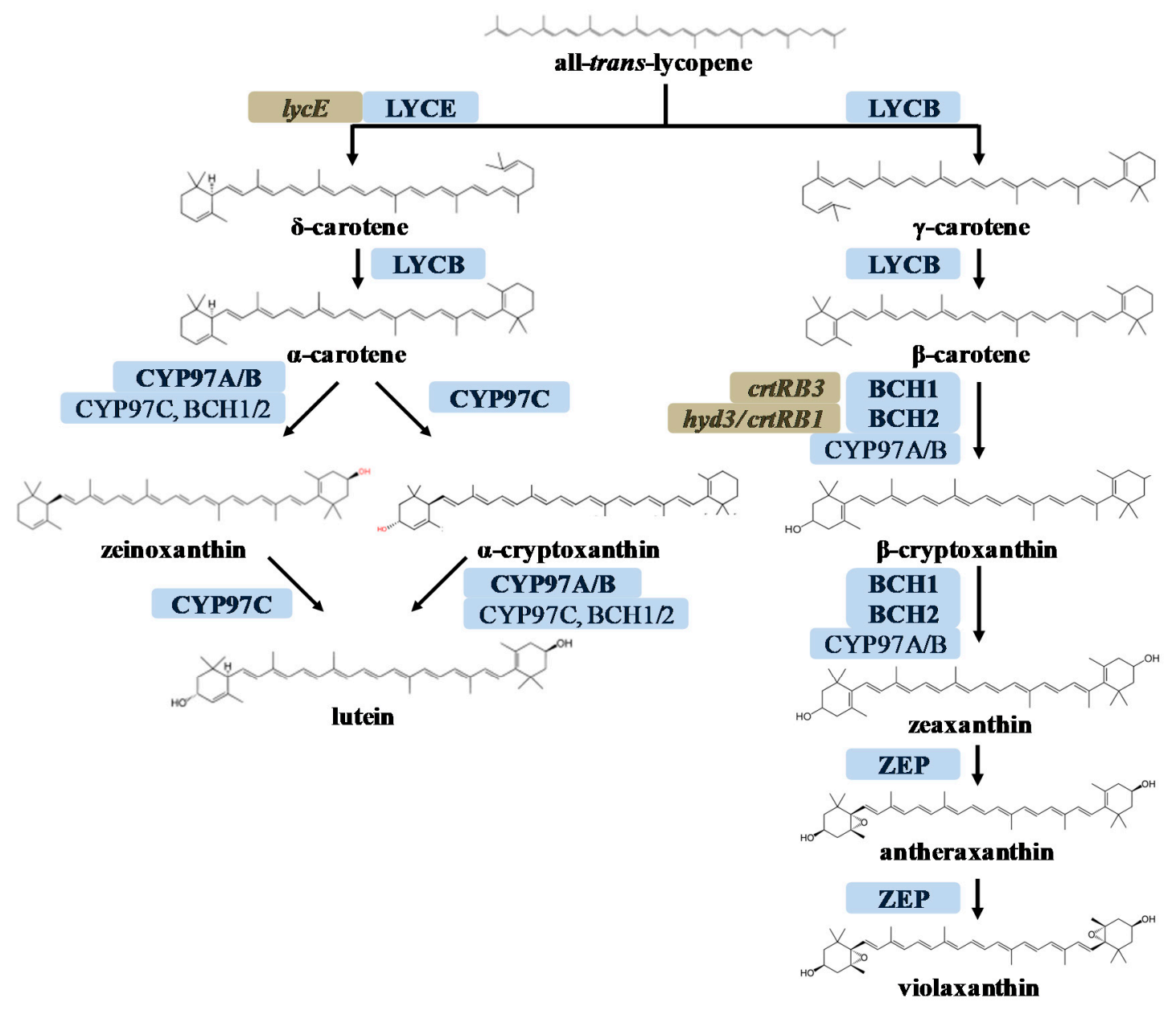

Figure 1. Xanthophyll biosynthesis pathway in maize endosperm. Enzymes responsible for the major activity at each step are shown in bold (blue). Identified maize locus names corresponding to each enzyme are shown in brown. Abbreviations: LYCB, lycopene $\beta$-cyclase; LYCE, lycopene $\varepsilon$-cyclase; CYP97C, heme-containing cytochrome $\mathrm{P} 450$ carotenoid $\varepsilon$-ring hydroxylase; CYP97A/B, heme-containing cytochrome $\mathrm{P} 450$ carotenoid $\beta$-ring hydroxylase; $\mathrm{BCH} 1 / 2$, Non-heme di-iron $\beta$-carotenoid hydroxylases; ZEP, zeaxanthin epoxidase. 
Two pairs of duplicated carotenoid hydroxylases have been identified in Arabidopsis thaliana $[9,10]$, tomato [11-13], rice [14,15], and maize [16-20]. These can be classified as non-heme di-iron hydroxylases ( $\mathrm{BCH}$ type) and heme-containing cytochrome $\mathrm{P} 450$ hydroxylases (CYP type). The $\mathrm{BCH}$ type enzymes $\mathrm{BCH} 1$ and $\mathrm{BCH} 2$ are primarily responsible for the hydroxylation of $\beta$-carotene and other $\beta, \beta$-carotenoids, although CYP-type enzymes can oxidize the $\beta$-rings of $\beta$-carotene to some extent in the A. thaliana bch1 bch 2 double mutant [9], and other CYP-type enzymes have also been shown to hydroxylate $\alpha$-carotene and/or $\beta$-carotene in plants and Escherichia coli $[10,14]$. For example, the tomato (Solanum lycopersicum) BCH-type enzymes CRTR-B1 and CRTR-B2, as well as CYP97A29, can hydroxylate the $\beta$-ring of $\alpha$-carotene [11-13].

Two maize $B C H$ genes ( $\mathrm{ZmBCH1}$ and $\mathrm{ZmBCH}$ ) ( $\mathrm{ZmBCH1}$, also termed ZmcrtRB3, or ZmHYD4; $\mathrm{ZmBCH} 2$ also termed $\mathrm{ZmcrtRB1}$, or $\mathrm{ZmHYD3}$ ) have been cloned and functionally characterized [16-19]. Candidate-gene association analysis identified 18 polymorphic sites in $\mathrm{ZmBCH1}$ significantly associated with one or more carotenoid-related traits in 126 diverse yellow maize inbred lines, indicating that $\mathrm{ZmBCH1}$ plays a role in hydroxylating the $\beta$-rings of $\alpha$-carotene and $\beta$-carotene, but predominantly $\alpha$-carotene [19]. In contrast, quantitative trait locus (QTL) mapping, genome-wide association studies (GWAS), and functional analysis revealed that $\mathrm{ZmBCH} 2$ strongly influences the conversion of $\beta$-carotene to zeaxanthin, with hypomorphic $\mathrm{ZmBCH} 2$ alleles correlating with higher $\beta$-carotene levels in the endosperm $[16,18,21,22]$. $\mathrm{ZmBCH} 2$ is also the only carotenoid hydroxylase gene expressed at high enough levels in maize endosperm to be detected by mRNA blot, and it is preferentially transcribed in the endosperm [17].

In potato (Solanuum tuberosum), silencing the BCH1 gene by RNA interference (RNAi) increased $\beta$-carotene levels from trace amounts in wild-type tubers to $3.31 \mu \mathrm{g} / \mathrm{g}$ fresh weight in the transgenic plants, with a concomitant loss of zeaxanthin and an increase in lutein [23]. The simultaneous silencing of both potato $B C H$ genes increased $\beta$-carotene levels by up to 38 -fold (with a concomitant loss of zeaxanthin) and the total carotenoid level increased by up to 4.5-fold [24]. Similarly, silencing $B C H$ expression in sweet orange plants (Citrus sinensis) produced oranges with a deep yellow color and up to 36-fold more $\beta$-carotene [25]. In wheat, blocking the expression of an endogenous $B C H$ gene promoted the conversion of $\beta$-carotene into xanthophylls, but nevertheless increased the $\beta$-carotene levels in the endosperm by up to 10-fold [26].

The ability to increase $\beta$-carotene levels in other crops by silencing one or more $B C H$ genes suggests that a similar strategy could be deployed in maize to address VAD in developing country populations. However, given the diverse activities of carotenoid $\beta$-hydroxylases in different crops, a functional analysis of the corresponding genes is necessary during the development of biotechnology programs to increase PVA levels. This is particularly important in maize due to the low ratio of PVA to non-PVA carotenoids in the endosperm and the diverse carotenoid profiles of different maize varieties [27]. In order to evaluate the impact of silencing both of the $\mathrm{BCH}$-type enzymes in different genetic backgrounds, we therefore introgressed $\mathrm{ZmBCH1/2}$ RNAi silencing cassettes into different lines and investigated the endosperm carotenoid content in the resulting hybrids.

\section{Results}

\subsection{RNAi-Mediated Silencing of $\mathrm{ZmBCH1}$ and $\mathrm{ZmBCH} 2$ in M37W White Maize}

The $\mathrm{ZmBCH} 1$ and $\mathrm{ZmBCH} 2$ DNA fragments used for RNAi construct show $96.4 \%$ identity, so the pHorP-RNAi-ZmBCH2 silencing construct was expected to downregulate not only the primary target $\mathrm{ZmBCH} 2$ but also the closely related paralog $\mathrm{ZmBCH} 1$ in M37W maize. This was confirmed by mRNA analysis. T3 endosperm from homozygous T2 plants was analyzed using selective probes for each transcript, revealing negligible levels of endogenous $\mathrm{ZmBCH} 2 \mathrm{mRNA}$ in two transgenic lines (M1 and M7) and low levels in two additional lines (M9 and M13) (Figure 2A). The ZmBCH1 transcript could not be detected in any of these lines by mRNA blot analysis so quantitative RT-PCR was used instead. 
This revealed that $\mathrm{ZmBCH1}$ was downregulated in all transgenic lines by at least two-fold, compared to M37W wild-type plants (Figure 2B).

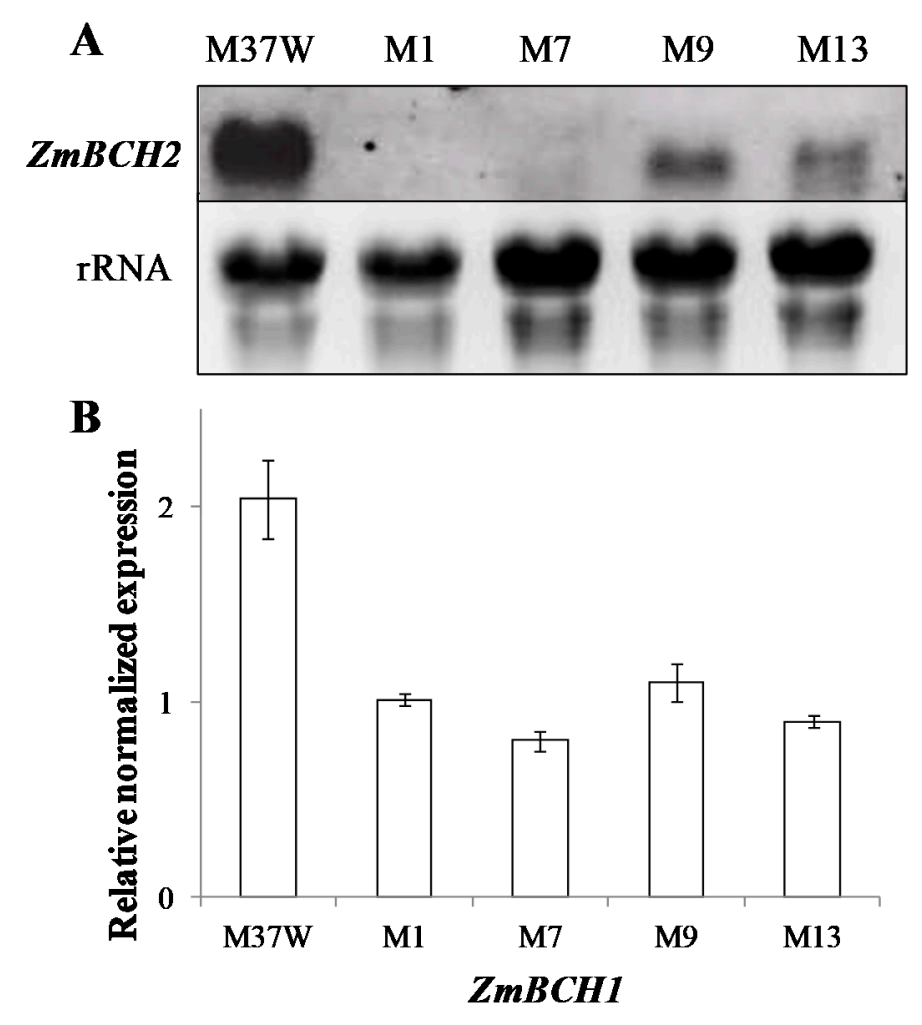

Figure 2. $B C H$ gene expression in the endosperm of wild-type (M37W) maize and independent transgenic lines M1, M7, M9, and M13 at 30 DAP. (A) An mRNA blot (25 $\mu$ g of total RNA per lane) to monitor ZmBCH2 expression; (B) Endogenous ZmBCH1 mRNA levels detected by qPCR presented as means of three replicates $\pm \mathrm{SE}$ (standard error).

\subsection{Carotenoid Profiles in Hybrids Derived from BCH-Silenced Parents}

Transgenic lines M7 and M13 were chosen to represent lines with near-complete $\mathrm{ZmBCH} 2$ silencing and partial $\mathrm{ZmBCH} 2$ silencing, respectively. Each transgenic line was crossed with a range of maize inbred lines to generate hybrids in different genetic backgrounds. The wild-type inbred parents were selected based on their diverse carotenoid profiles (Table S2). Inbred lines B73 and C17 accumulated lutein as the predominant carotenoid in the endosperm, whereas lines NC356, O1-3, O2-9, and PSY1 accumulated zeaxanthin instead. The purpose of these experiments was to investigate the impact of partial and near-complete $\mathrm{ZmBCH}$ gene silencing in diverse genetic backgrounds representing different expression levels of genes in the endogenous carotenoid biosynthesis pathway.

The endosperm carotenoid content and composition in transgenic lines M7 and M13 was similar to wild-type M37W plants. The transgenic lines accumulated $\sim 4.5 \mu \mathrm{g} / \mathrm{g}$ dry weight (DW) total carotenoids compared to $\sim 3 \mu \mathrm{g} / \mathrm{g}$ DW in the M37W parent. In both transgenic lines, zeaxanthin was much more abundant than lutein. Traces of antheraxanthin, a metabolic derivative of zeaxanthin (Figure 1), were detected in line M13 but not M7 (Figure 3, Table S1). 


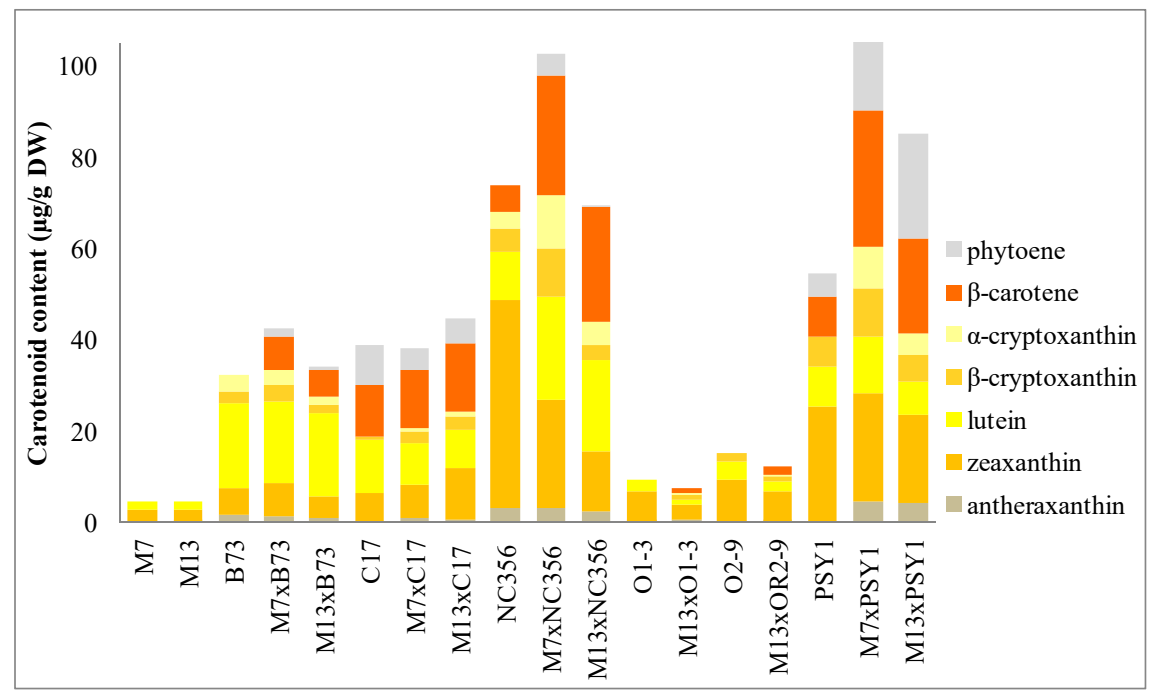

Figure 3. Carotenoid profiles in the endosperm (30 DAP) of parental lines M7, M13, B73, C17, NC356, O1-3, O2-9, PSY1, and the corresponding hybrids.

Among the selected inbred lines, B73 and C17 accumulated large quantities of $\beta, \varepsilon$-carotenoids [ $\alpha$-carotene $(\beta, \varepsilon$-carotene $)$ and its derived xanthophylls] but low quantities of $\beta, \beta$-carotenoids [ $\beta$-carotene $(\beta, \beta$-carotene) and its derived xanthophylls], and had similar total carotenoid levels in the endosperm but different carotenoid profiles. In line B73 (total carotenoid content $\sim 32 \mu \mathrm{g} / \mathrm{g}$ $\mathrm{DW})$, lutein was the predominant carotenoid $(\sim 19 \mu \mathrm{g} / \mathrm{g}$ DW) followed by zeaxanthin $(\sim 6 \mu \mathrm{g} / \mathrm{g} D W)$, $\alpha$-cryptoxanthin $(\sim 4 \mu \mathrm{g} / \mathrm{g}$ DW), $\beta$-cryptoxanthin $(\sim 3 \mu \mathrm{g} / \mathrm{g} \mathrm{DW})$, and antheraxanthin $(\sim 2 \mu \mathrm{g} / \mathrm{g} D W)$. In contrast, line C17 (total carotenoid content $\sim 39 \mu \mathrm{g} / \mathrm{g} D W)$ accumulated more lutein $(\sim 12 \mu \mathrm{g} / \mathrm{g} D W)$, $\beta$-carotene $(\sim 11 \mu \mathrm{g} / \mathrm{g} \mathrm{DW})$, and phytoene $(\sim 9 \mu \mathrm{g} / \mathrm{g} D W)$ than zeaxanthin $(\sim 6 \mu \mathrm{g} / \mathrm{g} \mathrm{DW})$, and also contained traces of $\beta$-cryptoxanthin $(\sim 1 \mu \mathrm{g} / \mathrm{g}$ DW).

The total carotenoid content of hybrids derived from lines B73 and C17 did not differ substantially from the levels detected in the inbred parents. In hybrid M7 $\times$ B73, the total carotenoid content increased by 1.3-fold to $\sim 42 \mu \mathrm{g} / \mathrm{g}$ DW, whereas in hybrid M13 $\times$ B73 the total carotenoid content increased by 1.1-fold to $\sim 34 \mu \mathrm{g} / \mathrm{g}$ DW. In hybrid M13 $\times \mathrm{C} 17$, the total carotenoid content increased by 1.1-fold to $\sim 45 \mu \mathrm{g} / \mathrm{g}$ DW, and the total carotenoid content of the $\mathrm{M} 7 \times \mathrm{C} 17$ hybrid was $\sim 38 \mu \mathrm{g} / \mathrm{g}$ DW, very slightly lower than the $\mathrm{C} 17$ parent. Although the total carotenoid levels showed little variation, we observed interesting changes in the carotenoid profiles of the hybrids compared to their parents. There were no significant changes in the level of $\beta, \varepsilon$-carotenoids in the B73 hybrids (M7 $\times$ B73 and M13 $\times$ B73), with lutein remaining the predominant carotenoid $(18-19 \mu \mathrm{g} / \mathrm{g}$ DW) and lower levels of $\alpha$-cryptoxanthin $(2-3 \mu \mathrm{g} / \mathrm{g}$ DW). In contrast, the M7 $\times \mathrm{C} 17$ and M13 $\times \mathrm{C} 17$ hybrids accumulated traces of $\alpha$-cryptoxanthin $(\sim 1 \mu \mathrm{g} / \mathrm{g} \mathrm{DW})$ that were not detected in the $\mathrm{C} 17$ parent, and lutein levels declined to $8-9 \mu \mathrm{g} / \mathrm{g}$ DW, representing a 1.3-1.4-fold decrease compared to C17.

The $\beta, \beta$-carotenoid profiles were particularly interesting because there were variations between different hybrids of the same parental line. In M7 $\times$ B73, the amount of zeaxanthin in the endosperm increased to $7 \mu \mathrm{g} / \mathrm{g}$ DW (1.2-fold increase compared to B73), but in M13 $\times$ B73 it fell to $5 \mu \mathrm{g} / \mathrm{g}$ DW (1.3-fold decrease compared to B73). The level of $\beta$-cryptoxanthin declined in both hybrids, to $\sim 3 \mu \mathrm{g} / \mathrm{g}$ DW (1.2-fold decrease) and $\sim 2 \mu \mathrm{g} / \mathrm{g}$ DW (1.4-fold decrease), respectively. Similarly, the level of antheraxanthin declined in both hybrids, to $1 \mu \mathrm{g} / \mathrm{g}$ DW (1.3-fold decrease) and $1 \mu \mathrm{g} / \mathrm{g}$ DW (1.7-fold decrease), respectively. Finally, although $\beta$-carotene was not detected in the B73 parent, the hybrids accumulated relatively large amounts $(\sim 6 \mu \mathrm{g} / \mathrm{g} D W)$ as well as traces of phytoene $(\sim 1 \mu \mathrm{g} / \mathrm{g} D W)$. However, in the $\mathrm{C} 17$ hybrids, $\beta$-carotene was the predominant carotenoid, increasing to $\sim 13 \mu \mathrm{g} / \mathrm{g}$ DW (1.1-fold increase compared to C17) and to $\sim 15 \mu \mathrm{g} / \mathrm{g}$ DW (1.2-fold increase) in the M7 $\times$ C17 and M13 $\times$ C17 hybrids, respectively. Furthermore, zeaxanthin levels increased to $\sim 7 \mu \mathrm{g} / \mathrm{g}$ DW (1.2-fold 
increase) and $11 \mu \mathrm{g} / \mathrm{g}$ DW ( 1.8-fold increase), respectively, and $\beta$-cryptoxanthin levels increased to $\sim 2.6 \mu \mathrm{g} / \mathrm{g}$ DW (4.3-fold increase) and $2.8 \mu \mathrm{g} / \mathrm{g}$ (4.7-fold increase), respectively. The level of phytoene declined to $\sim 5 \mu \mathrm{g} / \mathrm{g}$ DW (1.8-fold decrease) in both hybrids. No antheraxanthin was detected in the C17 parent, but $0.5-1 \mu \mathrm{g} / \mathrm{g}$ DW accumulated in the hybrids (Figure 3, Table S1).

The parental lines NC356, O1-3, O2-9 and PSY1 accumulated high levels of $\beta, \beta$-carotenoids but low levels of $\beta, \varepsilon$-carotenoids, and the total carotenoid levels and the profiles of different carotenoids differed considerably. NC356 accumulated the highest quantity of total carotenoids among the parental lines $(\sim 74 \mu \mathrm{g} / \mathrm{g} D W)$, predominantly zeaxanthin $(\sim 46 \mu \mathrm{g} / \mathrm{g} \mathrm{DW})$ and lutein $(\sim 11 \mu \mathrm{g} / \mathrm{g} D W)$, followed by $\beta$-carotene ( $\sim 6 \mu \mathrm{g} / \mathrm{g}$ DW; $9 \%$ of total carotenoids), $\beta$-cryptoxanthin ( $\sim \mu \mathrm{g} / \mathrm{g}$ DW; $7 \%$ of total carotenoids), $\alpha$-cryptoxanthin ( $\sim \mu \mathrm{g} / \mathrm{g}$ DW, $5 \%$ of total carotenoids), and antheraxanthin $(\sim 3 \mu \mathrm{g} / \mathrm{g}$ DW). O1-3, O2-9, and PSY1 are transgenic lines with the same M37W background. The carotenoid profiles of O1-3 and O2-9 (overexpressing the $A$. thaliana ORANGE gene, AtOR) were identical, but the total carotenoid content, and thus the abundance of individual carotenoids, was lower in line O1-3. We confirmed that the predominant carotenoid in line O1-3 (total carotenoid content $\sim 11 \mu \mathrm{g} / \mathrm{g}$ DW) was zeaxanthin $(\sim 6 \mu \mathrm{g} / \mathrm{g}$ DW), followed by lutein $(\sim 3 \mu \mathrm{g} / \mathrm{g} D W), \beta$-cryptoxanthin $(\sim 1 \mu \mathrm{g} / \mathrm{g} D W)$ and traces of antheraxanthin. The equivalent values for line O2-9 (total carotenoid content $\sim 15 \mu \mathrm{g} / \mathrm{g}$ DW) were $\sim 9 \mu \mathrm{g} / \mathrm{g}$ DW zeaxanthin, $\sim 4 \mu \mathrm{g} / \mathrm{g}$ DW lutein, and $\sim 2 \mu \mathrm{g} / \mathrm{g}$ DW $\beta$-cryptoxanthin. The total carotenoid content of line PSY1 was $54 \mu \mathrm{g} / \mathrm{g}$ DW, comprising $\sim 25 \mu \mathrm{g} / \mathrm{g}$ DW zeaxanthin, $\sim 9 \mu \mathrm{g} / \mathrm{g}$ DW $\beta$-carotene, $\sim 9 \mu \mathrm{g} / \mathrm{g}$ DW lutein, $\sim 7 \mu \mathrm{g} / \mathrm{g}$ DW $\beta$-cryptoxanthin, and $\sim 5 \mu \mathrm{g} / \mathrm{g}$ DW phytoene.

Hybrids derived from lines NC356 and PSY1 accumulated higher levels of carotenoids when crossed with line M7 than M13. The crosses M7 $\times$ O1-3 and M7 $\times$ O2-9 were not possible due to adverse field conditions so only the M13 $\times$ O1-3 and M13 $\times$ O2-9 hybrids were analyzed. The total carotenoid content of hybrid M7 × NC356 increased by 1.4-fold compared to NC356 ( 103 $\mu \mathrm{g} / \mathrm{g} \mathrm{DW})$, and that of M7 $\times$ PSY1 increased by 2-fold compared to PSY1 ( 106 $\mu \mathrm{g} / \mathrm{g}$ DW). The total carotenoid content of hybrid M13 $\times$ NC356 was similar to NC356 $(\sim 68 \mu \mathrm{g} / \mathrm{g}$ DW $)$, but that of M13 $\times$ PSY1 increased by 1.6 -fold compared to PSY1 $(\sim 85 \mu \mathrm{g} / \mathrm{g}$ DW). The total carotenoid content of hybrid M13 $\times$ O1-3 decreased by 1.4-fold compared to O1-3 $(\sim 8 \mu \mathrm{g} / \mathrm{g}$ DW $)$ and that of M13 $\times$ O2-9 decreased by 1.2 -fold compared to O2-9 ( 12 $\mu \mathrm{g} / \mathrm{g}$ DW).

The level of $\alpha$-cryptoxanthin increased in all six hybrids $(\mathrm{M} 7 \times \mathrm{NC} 356, \mathrm{M} 13 \times \mathrm{NC} 356, \mathrm{M} 13 \times \mathrm{O} 1-3$, M13 $\times$ O2-9, M7 $\times$ PSY1, and M13 $\times$ PSY1) compared to the parental lines. M7 $\times$ NC356 and M13 $\times$ NC356 accumulated $\sim 12$ and $\sim 5 \mu \mathrm{g} / \mathrm{g}$ DW, representing 3.2-fold and 1.4-fold increases, respectively, compared to NC356. Although M13 $\times$ O1-3 and M13 $\times$ O2-9 accumulated only traces of $\alpha$-cryptoxanthin, the parents O1-3 and O2-9 were entirely devoid of this carotenoid. More importantly, PSY1 also contained no traces of $\alpha$-cryptoxanthin, but the hybrids M7 $\times$ PSY1 and M13 $\times$ PSY1 accumulated $\sim 9$ and $\sim 5 \mu \mathrm{g} / \mathrm{g}$ DW, respectively.

The hybrids showed diverse lutein profiles. In M7 $\times$ NC356, the lutein level increased to $\sim 23 \mu \mathrm{g} / \mathrm{g}$ DW (2.1-fold more than NC356), and in M13 $\times$ NC356 it increased to $20 \mu \mathrm{g} / \mathrm{g}$ DW (1.9-fold more than NC356). In contrast, the lutein level in M13 $\times$ O1-3 decreased to $\sim 1 \mu \mathrm{g} / \mathrm{g}$ DW (2.4-fold less than O1-3), and in M13 $\times$ O2-9 it decreased to $\sim 2 \mu \mathrm{g} / \mathrm{g}$ DW (1.8-fold less than O2-9). Interestingly, the lutein content of M7 $\times$ PSY1 increased to $\sim 12 \mu \mathrm{g} / \mathrm{g}$ DW (1.4-fold more than PSY1), but in M13 $\times$ PSY1 it decreased to $\sim 7 \mu \mathrm{g} / \mathrm{g}$ DW (1.2-fold less than PSY1).

The $\beta$-cryptoxanthin content of the M7 hybrids was always higher than the corresponding parents, whereas in the M13 hybrids it was always lower. In both M7 $\times$ NC356 and M7 $\times$ PSY1, the level of $\beta$-cryptoxanthin was $\sim 11 \mu \mathrm{g} / \mathrm{g}$ DW (2.1-fold more than NC356, and 1.6-fold more than PSY1). In M13 $\times$ NC356, M13 $\times$ O1-3, M13 $\times$ O2-9, and M13 $\times$ PSY1, $\beta$-cryptoxanthin accumulated to $\sim 3 \mu \mathrm{g} / \mathrm{g}$ DW (1.7-fold less than NC356), 1 $\mu \mathrm{g} / \mathrm{g}$ DW (1.4-fold less than O1-3), $\sim 1 \mu \mathrm{g} / \mathrm{g}$ DW (1.6-fold less than O2-9), and $\sim 6 \mu \mathrm{g} / \mathrm{g}$ DW (1.1-fold less than PSY1), respectively.

Zeaxanthin levels decreased in most of the hybrids compared to their parents, with the exception of M7 $\times$ PSY1. M7 $\times$ NC356 and M13 $\times$ NC356 accumulated $\sim 24$ and $\sim 13 \mu \mathrm{g} / \mathrm{g}$ DW zeaxanthin (1.9-fold and 3.4-fold less than NC356), respectively. M13 $\times$ O1-3 and M13 $\times$ O2-9 accumulated 
$\sim 3$ and $\sim 7 \mu \mathrm{g} / \mathrm{g}$ DW zeaxanthin, respectively (1.9-fold less than O1-3 and 1.4-fold less than O2-9). Finally, M7 $\times$ PSY1 accumulated $\sim 24 \mu \mathrm{g} / \mathrm{g}$ DW zeaxanthin, which was similar to the PSY1 parent line, and M13 $\times$ PSY1 accumulated $19 \mu \mathrm{g} / \mathrm{g}$ DW zeaxanthin (1.3-fold less than PSY1).

The $\beta$-carotene content showed remarkable increases in all six hybrids compared to the corresponding parents. M7 $\times$ NC356 accumulated $\sim 26 \mu \mathrm{g} / \mathrm{g}$ DW (4.4-fold more than NC356), M13 $\times$ NC356 accumulated $25 \mu \mathrm{g} / \mathrm{g}$ DW (4.3-fold more than NC356), M7 $\times$ PSY1 accumulated $\sim 30 \mu \mathrm{g} / \mathrm{g}$ DW (3.4-fold more than PSY1), and M13 $\times$ PSY1 accumulated $\sim 21 \mu \mathrm{g} / \mathrm{g}$ DW (2.4-fold more than PSY1). M13 $\times$ O1-3 and M13 $\times$ O2-9 accumulated $\sim 1$ and $\sim 2 \mu \mathrm{g} / \mathrm{g}$ DW $\beta$-carotene, respectively, even though no traces of this carotenoid were found in the parents.

The upstream carotenoid phytoene, which was not detected in NC356, accumulated to $\sim 5 \mu \mathrm{g} / \mathrm{g}$ DW in M7 $\times$ NC356 and trace amounts were also found in M13 $\times$ NC356. In M7 $\times$ PSY1 and M13 $\times$ PSY1, the phytoene levels increased to $\sim 16$ and $\sim 23 \mu \mathrm{g} / \mathrm{g}$ DW (3.1-fold and 4.6-fold more than PSY1), respectively. Antheraxanthin, which was not detected in O2-9 or PSY1, accumulated to trace amounts in M13 $\times$ O2-9 and to $\sim 5 \mu \mathrm{g}$ and $4 \mu \mathrm{g} / \mathrm{g}$ DW in M7 $\times$ PSY1 and M13 $\times$ PSY1, respectively. The antheraxanthin content of the hybrids M7 $\times$ NC356 and M13 $\times$ O13 was similar to their parents, but the antheraxanthin content of the M13 $\times$ NC356 hybrid was $\sim 2 \mu \mathrm{g} / \mathrm{g}$ DW, which was 1.4-fold less than NC356 (Figure 3, Table S1).

\subsection{Analysis of Transgene and Endogenous Gene Expression in Hybrids Derived from BCH-Silenced Parents}

Transgene and endogenous gene expression was investigated by real-time RT-PCR and mRNA blot. AtOR expression was confirmed in the parental lines O1-3 and O2-9, and the corresponding hybrids M13 $\times$ O1-3 and M13 $\times$ O2-9. ZmPSY1 expression was confirmed in the PSY1 line and the corresponding hybrids M7 $\times$ PSY1 and M13 $\times$ PSY1 (Figure S1). A comparison of endogenous $\mathrm{ZmBCH1}, \mathrm{ZmBCH} 2, \mathrm{ZmCYP97A}, \mathrm{ZmCYP97B}$, and $\mathrm{ZmCYP97C}$ transcript levels relative to $\mathrm{ZmBCH1}$ revealed that the $Z m B C H 1$ and $Z m C Y P 97 C$ transcripts accumulated to similar levels in M37W endosperm. The levels of $Z m C Y P 97 A$ and $Z m C Y P 97 B$ expression in wild-type plants were 18-fold and 9-fold higher, respectively, than $\mathrm{ZmBCH1}$ expression, and $\mathrm{ZmBCH} 2$ mRNA was 150-fold more abundant than ZmBCH1 mRNA (Figure 4).

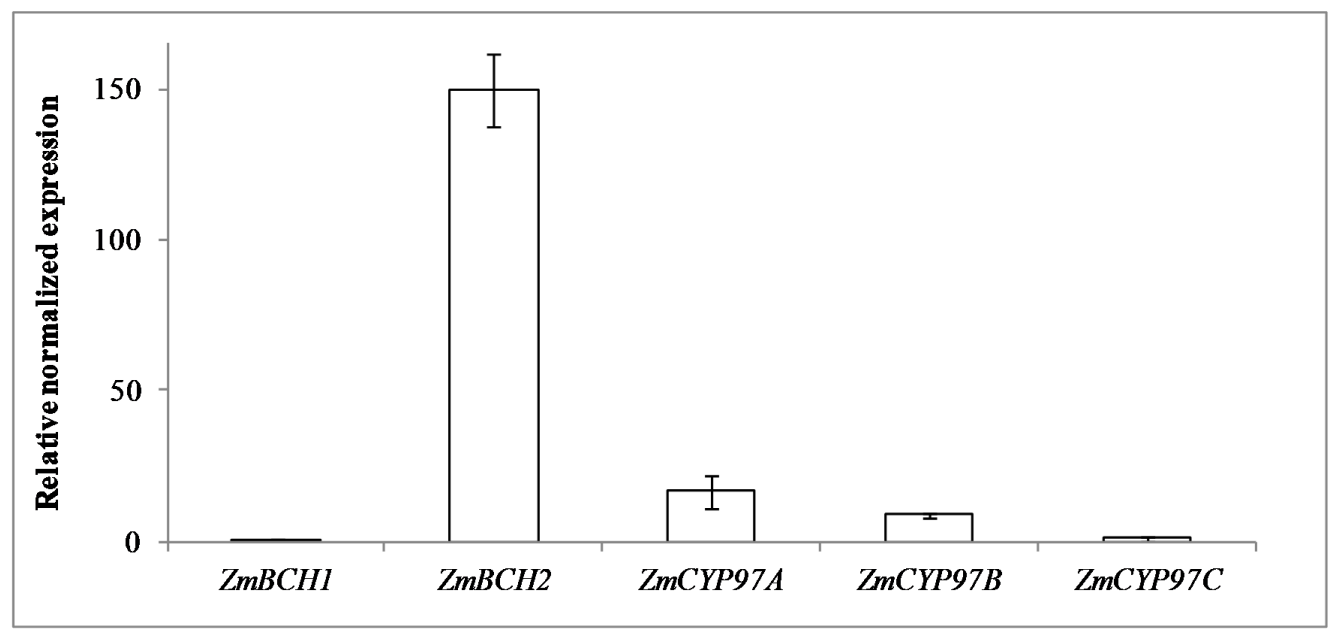

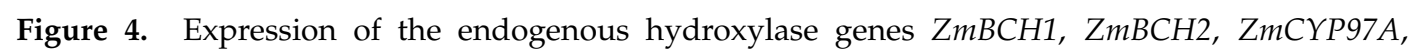
$\mathrm{ZmCYP97B}$, and $\mathrm{ZmCYP97C}$ in wild-type (M37W) maize endosperm (30 DAP), normalized against actin mRNA, relative to $Z m B C H 1$ and presented as the mean of three replicates $\pm \mathrm{SE}$.

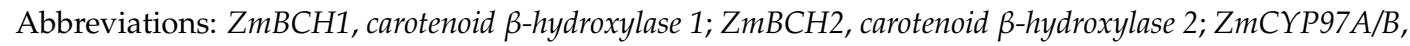
carotenoid $\beta$-hydroxylase; ZmCYP97C, carotenoid $\varepsilon$-hydroxylase. 
The expression of the endogenous hydroxylase genes $\mathrm{ZmBCH1}, \mathrm{ZmBCH} 2, \mathrm{ZmCYP97A}, \mathrm{ZmCYP97B}$, and $\mathrm{ZmCYP97C}$ was analyzed at 30 days after pollination (DAP) in the endosperm of the M37W, B73, C17, NC356, O1-3, O2-9 and PSY1 lines, and the corresponding hybrids generated with M7 and M13 (Figure 5). $\mathrm{ZmBCH1}$ and $\mathrm{ZmBCH} 2$ expression was downregulated in both transgenic lines ( 2-fold in M7 and 1.5-fold in M13) compared to wild-type plants. The levels of ZmCYP97A and ZmCYP97B mRNA were similar in M7, M13, and M37W, but ZmCYP97C levels were 3.5 -fold lower in the transgenic lines compared to M37W (Figure 5).

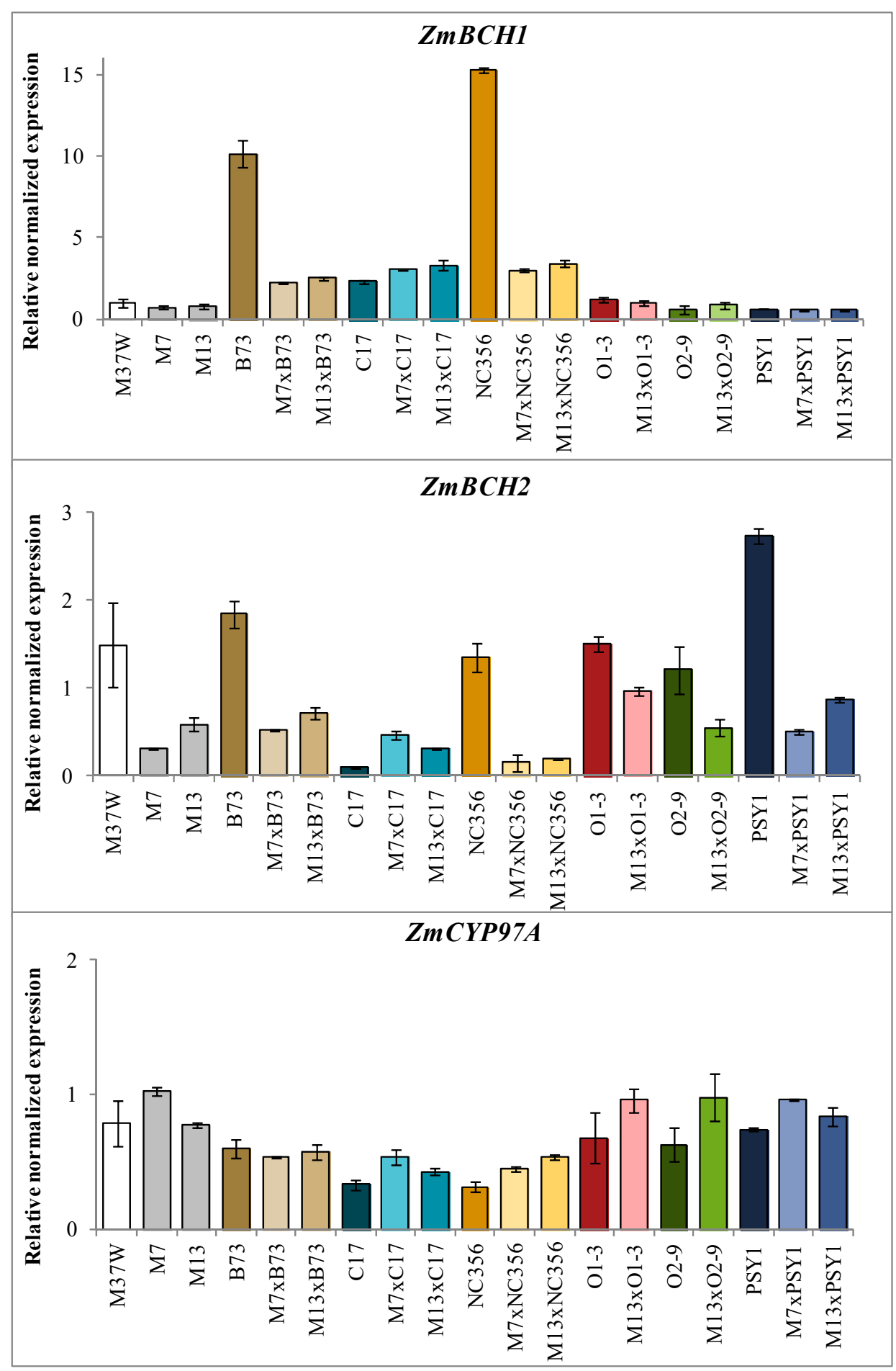

Figure 5. Cont. 


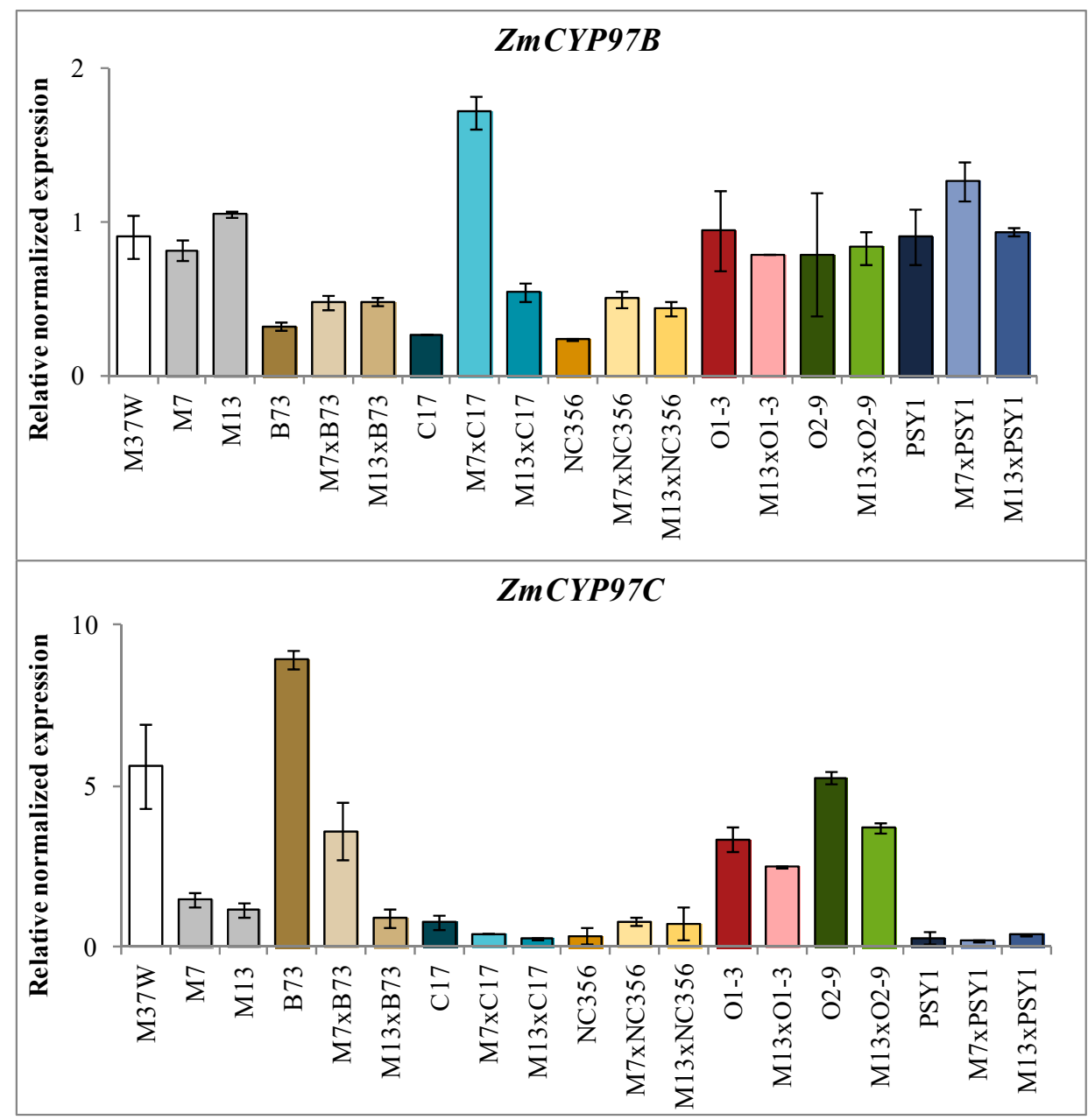

Figure 5. Expression of the endogenous hydroxylase genes $\mathrm{ZmBCH1}, \mathrm{ZmBCH} 2, \mathrm{ZmCYP97A}$, $\mathrm{ZmCYP97B}$, and ZmCYP97C in $30 \mathrm{DAP}$ maize endosperm, normalized against actin and relative to the expression levels in wild-type M37W maize and presented as the mean of three replicates $\pm \mathrm{SE}$.

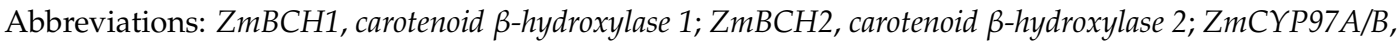
carotenoid $\beta$-hydroxylase; ZmCYP97C, carotenoid $\varepsilon$-hydroxylase.

ZmBCH1 was expressed at the highest levels in parental lines B73 and NC356 ( 10-fold and $\sim 15$-fold higher, respectively, than in the RNAi lines). In the hybrids derived from these parents $(\mathrm{M} 7 \times \mathrm{B} 73, \mathrm{M} 13 \times \mathrm{B} 73, \mathrm{M} 7 \times \mathrm{NC} 356$, and M13 $\times \mathrm{NC} 356), \mathrm{ZmBCH1}$ expression was partially silenced ( 5-fold lower than B73 and NC356). In line C17, ZmBCH1 mRNA was only 3-fold more abundant than in lines M7 and M13, and the corresponding hybrids M7 $\times$ C17 and M13 $\times$ C17 produced 1.3-fold more ZmBCH1 mRNA than the C17 parent. Endogenous ZmBCH1 expression was similar in lines O1-3, O2-9, PSY1, and the original wild-type progenitor M37W, but ZmBCH1 expression was not suppressed in the corresponding hybrids (M13 $\times$ O1-3, M13 $\times$ O2-9, M7 $\times$ PSY1, and M13 $\times$ PSY1) (Figure 5).

$\mathrm{ZmBCH} 2$ was expressed at the highest levels in parental lines B73, NC356, and PSY1 (approximately 2-fold, 1.6-fold, and 3.5-fold higher levels, respectively, compared to M13). In the M13 hybrids, $\mathrm{ZmBCH} 2$ was strongly downregulated compared to the levels in the wild-type parents (approximately 3-fold, 7-fold, and 3.5-fold compared to B73, NC356, and PSY1, respectively). ZmBCH2 expression in M13 $\times$ O1-3 and M13 $\times$ O2-9 was also reduced ( 2-fold) compared to parental lines O1-3 and O2-9. Because ZmBCH2 levels in M7 were lower than in M13, hybrids derived from M7 line were higher downregulated than hybrids derived from M13. In contrast, $\mathrm{ZmBCH} 2$ expression in parental line C17 was 4-fold lower compared to lines M7 and M13, and the corresponding hybrids 
M7 $\times$ C17 and M13 $\times$ C17 accumulated similar levels of $\mathrm{ZmBCH} 2 \mathrm{mRNA}$ compared to M7 and M13 parents (Figure 5).

ZmCYP97C transcript levels were $~ 9-$ fold higher in parental line B73 compared to M7 and M13, but in the corresponding hybrids (M7 $\times$ B73 and M13 $\times$ B73) they were $\sim 2.5$-fold and $\sim 9$-fold lower than B73, respectively (Figure 5). Similarly, ZmCYP97C levels were $\sim 4.5$-fold and $\sim 6$-fold higher in O1-3 and O2-9, respectively, compared to the M7 and M13 parents, and the corresponding hybrids (M13 $\times$ O1-3 and M13 $\times$ O2-9) accumulated 1.3-fold lower levels of ZmCYP97C mRNA than the O1-3 and O2-9 parents. ZmCYP97C mRNA levels in line C17 were similar to M7 and M13, but in the M7 $\times$ C17 and M13 $\times$ C17 hybrids they were 2-fold lower than in C17. However, ZmCYP97C mRNA levels in line NC356 were 4-fold lower than in M7 and M13, but the corresponding hybrids (M7 $\times$ NC356 and M13 $\times$ NC356) accumulated 2-fold higher levels of ZmCYP97C mRNA than NC356. ZmCYP97C mRNA levels in line PSY1 were 3-fold lower than in the M7 and M13 parents, and remained at this level in the hybrids M7 $\times$ PSY1 and M13 $\times$ PSY1 (Figure 5). The levels of ZmCYP97A and ZmCYP97B mRNA showed little variation between the parental lines and the corresponding hybrids (Figure 5).

\section{Discussion}

\subsection{Silencing the Endogenous $\mathrm{ZmBCH} 1$ and $\mathrm{ZmBCH} 2$ Genes Causes $\beta$-Carotene to Accumulate in the Endosperm of Diverse Maize Hybrids}

Transgenic maize plants in which both $\mathrm{ZmBCH} 1$ and $\mathrm{ZmBCH} 2$ were silenced simultaneously were generated because the RNAi cassette targeted a sequence conserved in both genes with $96.4 \%$ identity (Figure 2A,B). The potency of $\mathrm{ZmBCH} 2$ silencing varied among the transgenic lines, and we selected one line (M7) with near-complete $\mathrm{ZmBCH} 2$ silencing and another (M13) with partial $\mathrm{ZmBCH} 2$ silencing. $\mathrm{ZmBCH1}$ expression was already much lower than $\mathrm{ZmBCH} 2$ in the wild-type M37W endosperm and it declined by 2-fold in both M7 and M13. The M37W inbred line used for transformation only accumulates traces of carotenoids because the ZmPSY1 gene is expressed at low levels in the endosperm $[28,29]$. Consequently, primary transformants in an M37W genetic background cannot be used to evaluate the impact of $B C H$ gene silencing in the endosperm. We therefore introgressed the RNAi cassette present in lines M7 and M13 into different maize backgrounds selected on the basis of their endosperm carotenoid content and composition, to determine how the near-complete or partial silencing of $\mathrm{ZmBCH} 2$ affected carotenoid accumulation.

The carotenoid profiles of hybrids generated using transgenic lines M7 and M13 revealed diverse carotenoid profiles (Figure 3, Table S1). Silencing $\mathrm{ZmBCH1}$ and $\mathrm{ZmBCH} 2$ had a more profound impact on the $\beta, \beta$-carotenoid branch, given that the endosperm of parental lines $\mathrm{B} 73, \mathrm{O} 1-3$, and O2-9 contains no $\beta$-carotene but the corresponding hybrids accumulated up to $\sim 5 \mathrm{~g} / \mathrm{g}$ DW of this molecule. Furthermore, the NC356 and PSY1 hybrids accumulated up to 3.4-fold more $\beta$-carotene than their corresponding parents. However, no significant changes in $\beta$-carotene levels were detected in the $\mathrm{C} 17$ hybrids because $\mathrm{ZmBCH} 2$ is already expressed at minimal levels in the $\mathrm{C} 17$ parent (Figure 3). The levels of $\beta$-cryptoxanthin increased in all C17 hybrids but decreased in all O1-3 and O2-9 hybrids. Interestingly, the levels of $\beta$-cryptoxanthin increased when B73, NC356 and PSY1 were hybridized with the strongly-silenced line M7 but decreased when the same parents were hybridized with the partially silenced line $\mathrm{M} 13$, suggesting that the degree of $\mathrm{BCH}$ activity is a key determinant of $\beta$-cryptoxanthin levels. The M7 parent has a lower hydroxylation capacity than M13, so the monohydroxylated carotenoid $\beta$-cryptoxanthin accumulates at the expense of the dihydroxylated carotenoid zeaxanthin. Accordingly, zeaxanthin levels decreased when NC356, O1-3, and O2-9 were hybridized with either of the RNAi lines, but increased in all hybrids of B73 and PSY1, showing a correlation between the depleted zeaxanthin pool and the increase in $\beta$-carotene levels due to $\mathrm{ZmBCH} 2$ downregulation. This agrees with previous reports that $\mathrm{BCH} 2$ is the key determinant of the conversion of $\beta$-carotene into zeaxanthin in maize endosperm based on QTL mapping, GWAS and functional analysis [16-18,21,22].

In the $\alpha$-branch of the pathway, the $\beta$-hydroxylation of $\alpha$-cryptoxanthin produces lutein. We found that $\alpha$-cryptoxanthin accumulated in hybrids of C17, O1-3, O2-9, and PSY1 even though the parental 
lines do not produce this metabolite. In the M7 $\times$ B73 hybrid, the level of $\alpha$-cryptoxanthin was similar to that detected in the B73 parent, but the M13 $\times$ B73 hybrid produced more $\alpha$-cryptoxanthin than B73. Furthermore, both NC356 hybrids accumulated more $\alpha$-cryptoxanthin than the NC356 parent. The B73 and NC356 lines accumulated the highest levels of ZmBCH1 mRNA, but the presence of $\alpha$-cryptoxanthin suggests that additional hydroxylase activity is required for complete conversion to lutein. The quantity of lutein was reduced in the hybrids of lines C17, O1-3, and O2-9 compared to the parent lines, but increased in the NC356 hybrids and did not change in the PSY1 hybrids, again suggesting that additional $\beta$-hydroxylase activity (most likely provided by ZmCYP97A and/or $\mathrm{ZmCYP97B)} \mathrm{is} \mathrm{necessary} \mathrm{for} \mathrm{the} \mathrm{complete} \mathrm{conversion} \mathrm{of} \alpha$-cryptoxanthin into lutein. ZmCYP97A and/or ZmCYP97B orthologs in A. thaliana $[9,10]$, tomato [13], and rice $[14,15]$ are known to be involved in lutein biosynthesis.

\subsection{ZmBCH1 and ZmBCH2 Silencing Affects the Expression of CYP-Type $\varepsilon$-Hydroxylase Gene}

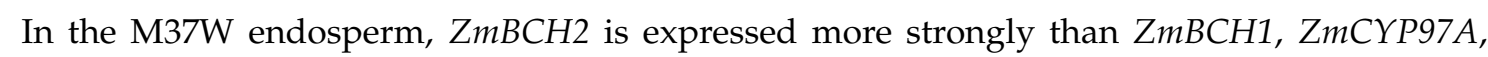
$\mathrm{ZmCYP97B}$, and $\mathrm{ZmCYP97C} \mathrm{(Figure} \mathrm{4).} \mathrm{ZmBCH1} \mathrm{is} \mathrm{more} \mathrm{important} \mathrm{for} \mathrm{the} \beta$-ring hydroxylation of $\alpha$-carotene than $\beta$-carotene, because polymorphisms in this gene correlated more with variations in $\alpha$-carotene levels rather than $\beta$-carotene levels [19]. ZmBCH1 mRNA levels varied widely in the different parental lines, with some lines accumulating up to 15 -fold higher levels of this transcript than M37W. ZmBCH1 mRNA levels were up to 5-fold lower in the B73 and NC356 hybrids than their parents, suggesting that $\mathrm{ZmBCH1}$ was strongly suppressed by the introgressed RNAi construct. However, there was little impact on $\mathrm{ZmBCH1}$ mRNA levels in hybrids of O1-3, O2-9, and PSY1, and ZmBCH1 mRNA levels in $\mathrm{C} 17$ hybrids were higher than in the $\mathrm{C} 17$ and M37W parents, suggesting that endogenous $\mathrm{ZmBCH1}$ alleles might influence the effectiveness of the RNAi construct introgressed into these hybrids. The strong suppression of $\mathrm{ZmBCH1}$ expression in hybrids of B73 and NC356 compared to the corresponding parental lines did not correlate with higher $\alpha$-cryptoxanthin and lower lutein levels, which suggests that additional carotenoid $\beta$-hydroxylase activity (probably $Z m C Y P 97 A$ and / or $Z m C Y P 97 B$, as stated above) may be required for the complete conversion of $\alpha$-cryptoxanthin into lutein. $\mathrm{ZmBCH} 2 \mathrm{mRNA}$ levels varied by only 2.5 -fold among all the parental lines and hybrids. However, the $\mathrm{ZmBCH} 2$ locus has a strong impact on $\beta$-carotene accumulation in the endosperm $[16,18]$ because it is the only hydroxylase gene strongly expressed in this tissue [17]. In most hybrids, $\mathrm{ZmBCH} 2 \mathrm{mRNA}$ levels were lower than in the corresponding parental lines, but the $\mathrm{C} 17$ hybrids were exceptional: the level of $\mathrm{ZmBCH} 2 \mathrm{mRNA}$ was lower than in the RNAi lines but higher than the C17 parent.

The different degrees of gene silencing in M7 and M13 also manifested in the hybrids derived from these lines. The levels of $Z m C Y P 97 A$ and $Z m C Y P 97 B$ mRNA in the parent lines and hybrids were too low to detect obvious differences, and any differences could reflect natural variations rather than the consequences of $B C H$ gene silencing. This low level of variability also suggests that $Z m C Y P 97 A$ and $Z m C Y P 97 B$ are tightly regulated. The levels of $Z m C Y P 97 A$ and $Z m C Y P 97 B$ were similar in hybrids and their parents, whereas the carotenoid $\varepsilon$-hydroxylase gene $Z m C Y P 97 C$ varied by up to 19-fold, with lines B73 and C17 representing the extremes. ZmCYP97C was downregulated in the hybrids of B73, C17, O1-3, and O2-9 compared to the parental lines, but not in hybrids of NC356 or PSY1. Interestingly, the NC356 or PSY1 hybrids did not show a reduction in lutein levels, suggesting that the downregulation of $\mathrm{BCH}$ gene expression may have a feedback effect on the genes encoding carotenoid $\varepsilon$-hydroxylases.

\section{Materials and Methods}

\subsection{Gene Cloning and Vector Construction}

The $\mathrm{ZmBCH} 2$ cDNA fragment was cloned from maize (Zea mays L. cv. B73) endosperm total RNA by RT-PCR using forward primer 5'-GGA ATT CTC TAG ACT ATC GCT TCA GCT GGC AAA 
TGG AG-3' (EcoRI and XbaI sites are underlined) and reverse primer $5^{\prime}$-GAC TAG TGG ATC CAA CTT GTC CAT GTG GTG TAT CTT G-3' (BamHI and SpeI sites are underlined) based on sequence information in GenBank (accession number: AY844958). The $\mathrm{ZmBCH} 2$ sequence was transferred to the $\mathrm{pHorP}$ vector containing the barley D-hordein promoter, a 300-bp gusA gene fragment, and the ADP-glucose pyrophosphorylase terminator (ADGPP) using restriction enzymes $\mathrm{XbaI}$ and $\mathrm{BamHI}$ to yield the intermediate vector $\mathrm{pHorP}-\mathrm{ZmBCH} 2$ sense. In a second step, the intermediate vector was digested with SpeI and EcoRI to introduce the antisense $\mathrm{ZmBCH} 2$ fragment between the gusA gene and ADGPP terminator, resulting in pHorP-RNAi-ZmBCH2 (Figure S2).

\subsection{Maize Transformation and Plant Growth}

We transformed 14-day-old immature zygotic embryos of South African elite white maize inbred M37W by bombarding them with gold particles coated with the pHorP-RNAi-ZmBCH2 construct and the bar gene for selection. Transgenic maize lines M1, M7, M9, and M13 were obtained following the procedure described by Zhu et al. (2008) [28]. Transgenic maize lines expressing AtOR (O1-3 and O2-9) and ZmPSY1 (PSY1) were described in our earlier studies [30]. Three inbred lines selected on the basis of their carotenoid profiles were obtained from the USDA or CSIC (Table S2). Homozygous M7, M13, O1-3, O2-9, B73, C17, and NC356 plants were self-pollinated as controls, or out-crossed with lines M7 and M13 (pollen donor) to obtain the hybrids M7 $\times$ B73, M7 $\times$ C17, M7 $\times$ NC356, M7 $\times$ PSY1, M13 $\times$ B73, M13 $\times$ C17, M13 $\times$ NC356, M13 $\times$ O1-3, M13 $\times$ O2-9, and M13 $\times$ PSY1. For further analysis, endosperm samples were taken from immature seeds $30 \mathrm{DAP}$, frozen in liquid nitrogen, and stored at $-80^{\circ} \mathrm{C}$.

\subsection{RNA Extraction and Expression Analysis}

Total RNA was extracted for mRNA blot analysis and cDNA synthesis as previously described [29]. Quantitative real-time PCR (qRT-PCR) was carried out in triplicate using the primers listed in Table S3. Real-time RT-PCR was performed on a BioRad CFX96TM system using $25-\mu \mathrm{L}$ mixtures containing $10 \mathrm{ng}$ of synthesized cDNA, $1 \times$ iQ SYBR Green Supermix (BioRad, Hercules, CA, USA), and $0.2 \mu \mathrm{M}$ forward and reverse primers. Relative expression levels were calculated on the basis of serial dilutions of cDNA (125-0.2 ng), which were used to generate standard curves for each gene. Cycling conditions consisted of a single incubation step at $95^{\circ} \mathrm{C}$ for 5 min followed by 30 cycles of $95^{\circ} \mathrm{C}$ for $10 \mathrm{~s}, 58{ }^{\circ} \mathrm{C}$ for $35 \mathrm{~s}$, and $72{ }^{\circ} \mathrm{C}$ for $15 \mathrm{~s}$. Specificity was confirmed by product melt curve analysis over the temperature range $50-90^{\circ} \mathrm{C}$ with fluorescence acquired after every $0.5^{\circ} \mathrm{C}$ increase, and the fluorescence threshold value and gene expression data were calculated with BioRad CFX manager software version 3.1. Values represent the mean of three biological replicates $\pm \mathrm{SE}$. Amplification efficiencies were compared by plotting the $\Delta C_{t}$ values of different primer combinations of serial dilutions against the log of starting template concentrations using the CFX96TM software. Differences among samples were observed by mean \pm SE.

\subsection{Carotenoid Extraction and UPLC (Ultra Performance Liquid Chromatography) Analysis}

Carotenoids were extracted from 30 DAP maize endosperm for UPLC analysis in triplicate as described by Berman et al. [30]. Data were calculated from three replicates with error bars representing the standard error. Differences among samples were observed by mean $\pm \mathrm{SE}$.

\section{Conclusions}

The RNAi-ZmBCH2 cassette in transgenic lines M7 and M13 was introgressed into several maize genetic backgrounds with different carotenoid profiles. Knocking down endogenous $\mathrm{ZmBCH} 2$ expression by RNAi increased $\beta$-carotene levels in hybrids of the parental lines B73, N356, O1-3, O2-9, and PSY1, regardless of whether or not the endogenous $\mathrm{ZmBCH1}$ gene was also affected. However, we detected no change in the level of $\beta$-carotene in hybrids of $\mathrm{C} 17(\mathrm{M} 7 \times \mathrm{C} 17$ and M13 $\times \mathrm{C} 17)$ as compared to the $\mathrm{C} 17$ parent because $\mathrm{ZmBCH} 2$ transcript levels were already very low. These results 
indicate that $\mathrm{ZmBCH} 2$ is the critical enzyme responsible for the conversion of $\beta$-carotene to zeaxanthin via $\beta$-cryptoxanthin in maize endosperm, and that its activity may be intimately linked with that of the carotenoid $\varepsilon$-hydroxylase encoded by ZmCYP97C.

Supplementary Materials: Supplementary materials can be found at www.mdpi.com/1422-0067/18/12/2515/s1.

Acknowledgments: This work was supported by MINECO (Ministry of Economy and Competitiveness), Spain (BIO2014-54441-P; BIO2014-54426-P) and the National Natural Science Foundation of China (31470394); COSTaction (EUROCAROTEN, OC-2015-1-19780).

Author Contributions: Teresa Capell, Paul Christou, and Changfu Zhu conceived and designed research. Judit Berman, Uxue Zorrilla-López, Gerhard Sandmann, Teresa Capell, and Changfu Zhu conducted experiments. Judit Berman, Uxue Zorrilla-López, Gerhard Sandmann, Teresa Capell, and Changfu Zhu contributed new reagents or analytical tools. Judit Berman, Gerhard Sandmann, Teresa Capell, Paul Christou, and Changfu Zhu analyzed data. Judit Berman, Paul Christou, and Changfu Zhu wrote the manuscript. All authors read and approved the manuscript.

Conflicts of Interest: The authors declare no conflict of interest.

\section{References}

1. Bai, C.; Twyman, R.M.; Farré, G.; Sanahuja, G.; Christou, P.; Capell, T.; Zhu, C. A golden era-Pro-vitamin A enhancement in diverse crops. In Vitro Cell. Dev. Biol. Plant 2011, 47, 205-221. [CrossRef]

2. Farré, G.; Bai, C.; Twyman, R.M.; Capell, T.; Christou, P.; Zhu, C. Nutritious crops producing multiple carotenoids-A metabolic balancing act. Trends Plant Sci. 2011, 16, 532-540. [CrossRef] [PubMed]

3. Berman, J.; Zorrilla-López, U.; Farré, G.; Zhu, C.; Sandmann, G.; Twyman, R.M.; Capell, T.; Christou, P. Nutritionally important carotenoids as consumer products. Phytochem. Rev. 2015, 14, 727-743. [CrossRef]

4. Zhu, C.; Naqvi, S.; Gomez-Galera, S.; Pelacho, A.M.; Capell, T.; Christou, P. Transgenic strategies for the nutritional enhancement of plants. Trends Plant Sci. 2007, 12, 548-555. [CrossRef] [PubMed]

5. Berman, J.; Zhu, C.; Pérez-Massot, E.; Arjó, G.; Zorrilla-López, U.; Masip, G.; Banakar, R.; Sanahuja, G.; Farré, G.; Miralpeix, B.; et al. Can the world afford to ignore biotechnology solutions that address food insecurity? Plant Mol. Biol. 2013, 83, 5-19. [CrossRef] [PubMed]

6. Farré, G.; Sanahuja, G.; Naqvi, S.; Bai, C.; Capell, T.; Zhu, C.; Christou, P. Travel advice on the road to carotenoids in plants. Plant Sci. 2010, 179, 28-48. [CrossRef]

7. Farré, G.; Blancquaert, D.; Capell, T.; Van Der Straeten, D.; Christou, P.; Zhu, C. Engineering complex metabolic pathways in plants. Annu. Rev. Plant Biol. 2014, 65, 187-223. [CrossRef] [PubMed]

8. Rodríguez-Concepción, M. Supply of precursors for carotenoid biosynthesis in plants. Arch. Biochem. Biophys. 2010, 504, 118-122. [CrossRef] [PubMed]

9. Kim, J.; Smith, J.J.; Tian, L.; DellaPenna, D. The evolution and function of carotenoid hydroxylases in Arabidopsis. Plant Cell Physiol. 2009, 50, 463-479. [CrossRef] [PubMed]

10. Kim, J.E.; Cheng, K.M.; Craft, N.E.; Hamberger, B.; Douglas, C.J. Over-expression of Arabidopsis thaliana carotenoid hydroxylases individually and in combination with a beta-carotene ketolase provides insight into in vivo functions. Phytochemistry 2010, 71, 168-178. [CrossRef] [PubMed]

11. Galpaz, N.; Ronen, G.; Khalfa, Z.; Zamir, D.; Hirschberg, J. A chromoplast-specific carotenoid biosynthesis pathway is revealed by cloning of the tomato white-flower locus. Plant Cell 2006, 18, 1947-1960. [CrossRef] [PubMed]

12. D'Ambrosio, C.; Stigliani, A.L.; Giorio, G. Overexpression of $C r t R-b 2$ (carotene $\beta$ hydroxylase 2) from S. lycopersicum L. differentially affects xanthophyll synthesis and accumulation in transgenic tomato plants. Transgenic Res. 2011, 20, 47-60. [CrossRef] [PubMed]

13. Stigliani, A.L.; Giorio, G.; D'Ambrosio, C. Characterization of P450 carotenoid $\beta$ - and epsilon-hydroxylases of tomato and transcriptional regulation of xanthophyll biosynthesis in root, leaf, petal and fruit. Plant Cell Physiol. 2011, 52, 851-865. [CrossRef] [PubMed]

14. Quinlan, R.F.; Jaradat, T.T.; Wurtzel, E.T. Escherichia coli as a platform for functional expression of plant P450 carotene hydroxylases. Arch. Biochem. Biophys. 2007, 458, 146-157. [CrossRef] [PubMed]

15. Lv, M.Z.; Chao, D.Y.; Shan, J.X.; Zhu, M.Z.; Shi, M.; Gao, J.P.; Lin, H.X. Rice carotenoid $\beta$-ring hydroxylase CYP97A4 is involved in lutein biosynthesis. Plant Cell Physiol. 2012, 53, 987-1002. [CrossRef] [PubMed] 
16. Vallabhaneni, R.; Gallagher, C.E.; Licciardello, N.; Cuttriss, A.J.; Quinlan, R.F.; Wurtzel, E.T. Metabolite sorting of a germplasm collection reveals the hydroxylase 3 locus as a new target for maize provitamin A biofortification. Plant Physiol. 2009, 151, 1635-1645. [CrossRef] [PubMed]

17. Li, Q.; Farre, G.; Naqvi, S.; Breitenbach, J.; Sanahuja, G.; Bai, C.; Sandmann, G.; Capell, T.; Christou, P.; Zhu, C. Cloning and functional characterization of the maize carotenoid isomerase and $\beta$-carotene hydroxylase genes and their regulation during endosperm maturation. Transgenic Res. 2010, 19, 1053-1068. [CrossRef] [PubMed]

18. Yan, J.; Kandianis, C.B.; Harjes, C.E.; Bai, L.; Kim, E.; Yang, X.; Skinner, D.J.; Fu, Z.; Mitchell, S.; Li, Q.; et al. Rare genetic variation at Zea mays crtRB1 increases $\beta$-carotene in maize grain. Nat. Genet. 2010, 42, 322-327. [CrossRef] [PubMed]

19. Zhou, Y.; Han, Y.; Li, Z.; Fu, Y.; Fu, Z.; Xu, S.; Li, J.; Yan, J.; Yang, X. ZmcrtRB3 encodes a carotenoid hydroxylase that affects the accumulation of $\alpha$-carotene in maize kernel. J. Integr. Plant Biol. 2012, 54, 260-269. [CrossRef] [PubMed]

20. Chang, S.; Berman, J.; Sheng, Y.; Wang, Y.; Capell, T.; Shi, L.; Ni, X.; Sandmann, G.; Christou, P.; Zhu, C. Cloning and functional characterization of the maize (Zea mays L.) carotenoid epsilon hydroxylase gene. PLoS ONE 2015, 10, e0128758. [CrossRef] [PubMed]

21. Babu, R.; Palacios Rojas, N.; Gao, S.; Yan, J.; Prixley, K. Validation of the effects of molecular marker polymorphisms in $L c y E$ and CrtRB1 on provitamin A concentrations for 26 tropical maize populations. Theor. Appl. Genet. 2013, 126, 389-399. [CrossRef] [PubMed]

22. Owens, B.F.; Lipka, A.E.; Magallanes-Lundback, M.; Tiede, T.; Diepenbrock, C.H.; Kandianis, C.B.; Kim, E.; Cepela, J.; Mateos-Hernandez, M.; Buell, C.R.; et al. A foundation for provitamin A biofortification of maize: Genome-wide association and genomic prediction models of carotenoid levels. Genetics 2014, 198, 1699-1716. [CrossRef] [PubMed]

23. Van Eck, J.; Conlin, B.; Garvin, D.F.; Mason, H.; Navarre, D.; Brown, C.R. Enhancing beta-carotene content in potato by RNAi-mediated silencing of the beta-carotene hydroxylase gene. Am. J. Potato Res. 2007, 84, 331-342. [CrossRef]

24. Diretto, G.; Welsch, R.; Tavazza, R.; Mourgues, F.; Pizzichini, D.; Beyer, P.; Giuliano, G. Silencing of beta-carotene hydroxylase increases total carotenoid and beta-carotene levels in potato tubers. BMC Plant Biol. 2007, 7, 11. [CrossRef] [PubMed]

25. Pons, E.; Alquézar, B.; Rodríguez, A.; Martorell, P.; Genovés, S.; Ramón, D.; Rodrigo, M.J.; Zacarías, L.; Peña, L. Metabolic engineering of $\beta$-carotene in orange fruit increases its in vivo antioxidant properties. Plant Biotechnol. J. 2014, 12, 17-27. [CrossRef] [PubMed]

26. Zeng, J.; Wang, X.T.; Miao, Y.J.; Wang, C.; Zang, M.L.; Chen, X.; Li, M.; Li, X.; Wang, Q.; Li, K.; et al. Metabolic engineering of wheat provitamin A by simultaneously overexpressing $C r t B$ and silencing carotenoid hydroxylase (TaHYD). J. Agric. Food Chem. 2015, 63, 9083-9092. [CrossRef] [PubMed]

27. Harjes, C.E.; Rocheford, T.R.; Bai, L.; Brutnell, T.P.; Kandianis, C.B.; Sowinski, S.G.; Stapleton, A.E.; Vallabhaneni, R.; Williams, M.; Wurtzel, E.T.; et al. Natural genetic variation in lycopene epsilon cyclase tapped for maize biofortification. Science 2008, 319, 330-333. [CrossRef] [PubMed]

28. Zhu, C.; Naqvi, S.; Breitenbach, J.; Sandmann, G.; Christou, P.; Capell, T. Combinatorial genetic transformation generates a library of metabolic phenotypes for the carotenoid pathway in maize. Proc. Natl. Acad. Sci. USA 2008, 105, 18232-18237. [CrossRef] [PubMed]

29. Naqvi, S.; Zhu, C.; Farre, G.; Sandmann, G.; Capell, T.; Christou, P. Synergistic metabolism in hybrid corn indicates bottlenecks in the carotenoid pathway and leads to the accumulation of extraordinary levels of the nutritionally important carotenoid zeaxanthin. Plant Biotechnol. J. 2011, 9, 384-393. [CrossRef] [PubMed]

30. Berman, J.; Zorrilla-López, U.; Medina, V.; Farré, G.; Sandmann, G.; Capell, T.; Christou, P.; Zhu, C. The Arabidopsis ORANGE (AtOR) gene promotes carotenoid accumulation in transgenic corn hybrids derived from parental lines with limited carotenoid pools. Plant Cell Rep. 2017, 36, 933-945. [CrossRef] [PubMed]

(C) 2017 by the authors. Licensee MDPI, Basel, Switzerland. This article is an open access article distributed under the terms and conditions of the Creative Commons Attribution (CC BY) license (http:/ / creativecommons.org/licenses/by/4.0/). 